\title{
CEREBRAL METASTASIS IN ASSOCIATION WITH INTRATHORACIC DISEASE
}

\author{
By Maurice Davidson, M.A., D.M., F.R.C.P. \\ Physician, Brompton Hospital for Diseases of the Chest; Consulting Physician, Miller General Hospital for \\ South-East London
}

The following case reports seemed to me to be worth recording; the phenomena with which they deal, though well recognized in medical literature, are not so commonly encountered in general practice ; in one, especially (Case 3 ), the difficulty in diagnosis in the earlier stages of the illness was not inconsiderable and gave rise to much interesting discussion.

The association bétween bronchiectasis and cerebral abscess has always been admitted; reference to it is to be found in most standard works on general medicine. Jex-Blake (1920) in a survey of 110 cases records intracranial abscess as the cause of death in 15 , i.e., in 13.63 per cent. Kent and Blades (1942) refer to metastatic abscess in connection with intrathoracic suppuration as occurring almost exclusively in the brain, rarely in other organs. Collis (1944) discussing a series of cases collected from the Brompton Hospital, from an E.M.S. chest centre, and from the Birmingham United Hospitals, reviews some of the literature on the subject. His own figure of three cases of cerebral complication in 54 deaths from bronchiectasis at Brompton, between 1933 and I938 only, gives an incidence of 5.5 per cent. ; with empyema he found that the cerebral complications occurred in 1.9 per cent. of cases and accounted for 16 per cent. of the mortality of the condition, and with lung abscess the corresponding figures were 4.5 per cent. and 20 per cent. He agrees with Schorstein as saying that 20 per cent. of bronchiectatic patients eventually develop a cerebral complication; it must be remembered, however, that in the earlier days of the work at Brompton, before the introduction of bronchography, many cases of bronchiectasis, in which infection played but a negligible part, must have passed unrecognized, and that therefore the earlier statistics are probably to some extent misleading. Nickerson (1935) in a record of 10,502 unselected autopsies found 12 instances of cerebral abscess associated with thoracic disease. Russell Brain (1947) dealing with the causes of cerebral abscess puts these in order of frequency as (I) Infection of the middle ear, mastoid and nasal sinuses ; (2) pyaemic states ; (3) metastasis from intrathoracic suppuration; (4) head injury; a statement which is generally - corroborated by other neurological authorities.

Enough has been said by way of introduction to indicate the importance of this aspect of chest disease, though it may, perhaps, be observed in parenthesis that brain abscesses do not occur in connection with acute empyema, but only after the chronic variety of at least three months duration and usually much more, and that in fatal cases death takes place with considerable rapidity (Schorstein notes the occurrence of death within an average period of ro days, and Collis within 13 days).

\section{Case 1. Chronic Empyema-Cerebral} Abscess

This was a man aged 59 who, in 1916 , had an empyema following an attack of acute lobar (pneumococcal) pneumonia. The usual operation of thoracotomy with rib resection had been performed for drainage of the empyema, with apparently complete recovery. In 1920 a staphylococcal abscess developed under the old operation scar, and it was then found in the course of routine examination that a broncho-pleural fistula was present. He again made what seemed to be a complete recovery, but for the next three years he suffered from occasional attacks of haemoptysis, which did not, however, constitute a serious disability or prevent him from carrying out his ordinary duties, which were of a fairly strenuous character.

In the early part of 1933 he began to expectorate a small quantity of sputum, which was occasionally blood-stained, and about this time he began to complain of a certain amount of lassitude. On clinical examination it was evident that the drainage of the original empyema had been inadequate, and surgical exploration was considered advisable. A large exploring needle was introduced under general anaesthesia just above the middle of the original scar ; an extremely thick and tough pleural membrane was pierced and a little thick pus was withdrawn. An incision was then made along the line of the scar and about an inch of rib was resected. The pleura when incised was found to be 
about an inch thick; a small pocket about the size of a tangerine orange, or rather less, was found. From the escape of air through the wound during expiration it was evident that there was a broncho-pleural fistula. A short rubber drainage tube was inserted into the cavity, and the wound was closed.

After this operation the patient improved, the cough becoming less, with only a trace of mucoid sputum in the morning. About three weeks later, however, the temperature, which had been normal for some time, rose again to $100^{\circ}$ at night, and the discharge from the tube increased somewhat. The sinus was dilated by the introduction of bougies, a large drainage tube being subsequently introduced. The discharge now amounted to an ounce to two ounces a day; the bronchial fistula was still evident from the escape of air whenever the patient coughed or made a forced expiration.

A second operation was undertaken with the object of establishing more satisfactory drainage. The old scar and the mouth of the sinus were excised with the diathermy cautery, the incision being prolonged backwards. It became evident that the cavity extended well back and about an inch and a half above the sinus. The bronchial fistula was demonstrated, two small bronchi being seen opening into a thin portion of the cavity wall. The cavity, which extended from the midaxillary line to the costo-vertebral angle, was finally packed with gauze soaked in flavine-paraffin.

Five days after this last operation it was observed that the patient had some little difficulty in his speech ; he had a slight degree of mental confusion, and there was some clumsiness in the movements of the right hand, though no loss of power was noticed (a similar phenomenon had been observed about a year previously, the symptoms lasting about a week). The following day aphasia was more marked, and right-sided facial weakness was apparent, with some loss of power in the right arm and leg; the abdominal reflexes were absent, and the plantar reflexes showed an extensor response on both sides. Next day aphasia was extreme and the patient's general condition was obviously much worse; the day after this his respirations became shallow and the pulse was weaker, and he died early the next morning. No autopsy was permitted in this case, but from the clinical course of events it is obvious that death was due to a metastatic abscess in the left side of the brain, succeeding a chronic pyogenic infection of the pleural cavity.

\section{Case 2. Chronic Pulmonary Tuberculosis - Cerebral Abscess}

This patient, a medical practitioner, died at the age of 74 of cerebral abscess. The clinical history is of considerable interest, since no objective signs of disease, either of the lungs or of the centra nervous system, had ever manifested themselves until a few weeks before death occurred. The patient had retired from active practice about te $\vec{f}$ years before his decease, and had been leading comparatively quiet life devoted to medical ang general literary study. The first sign of an serious disturbance of normal health was a sudde slight aphasic manifestation. He had noticed a certain lack of mental orientation while doing crossword puzzle; he had also had difficulty $i \vec{B}$ reading his favourite Greek authors, the sequence of thought and the significance of words and phrases being suddenly interrupted, an experienes which, since he was a classical scholar of out standing ability, caused him considerable ment a distress.

It was shortly after this that I was asked to see him on account of general malaise and slight feve品 which eventually ended in a terminal pneumonia which was the immediate cause of death Throughout the last illness persistence of the aphasia was a prominent feature. It took the form of an obvious disorientation of cerebral associae tion, certain words being invariably substituted fơ others in a sentence, though the ability to main tain intelligible conversation was more or less ens impaired. Examination of the central nervefus system showed no localizing signs of a cere lesion, and consciousness and intelligence were maintained to within a few days of death, which as already mentioned, was due to an acute terminat pneumonia.

Autopsy on this patient revealed a large abscest' cavity in the left temporo-sphenoidal lobe. This cavity contained several ounces of pus of a bright greenish-blue colour, suggestive of infection wit B.Pyocyaneus. Examination of the lungs showed pneumonic consolidation of both lower lobes, but there was evidence of old chronic fibro-caseous tuberculosis at both apices, with racemose tuber culous lesions of more recent date in the uppes zones of both lungs below the apical regions. $A \overline{\text { Q }}$ no time during life had this patient ever suffere $\$$ from any symptoms suggestive of a pulmonary lesion, the only indication of ill-health being the gradual onset of such general symptoms as ares commonly associated with the decline of advancing years.

It was evident that the cerebral abscess must have been present for some considerable times The conclusion reached by myself and the patholeo gist who conducted the autopsy was that the original lesion in the brain must have been $\%$ tuberculoma, secondary to clinically silent tuber $D$ culous lesions of the lungs, and subsequently in fected by the B.Pyocyaneus. 


\section{Case 3. Bronchiectasis - Empyema - Cerebral Abscess}

This was a girl of 18 whose clinical history and course were so eventful and who presented such an interesting and difficult problem in differential diagnosis that $I$ have felt it worth while to record the case in considerable detail.

She was originally sent to me for advice in 1945 with a history of long standing respiratory catarrh. In early childhood she had had an operation for the removal of tonsils and adenoids, since which she suffered each winter from recurrent colds with much cough and expectoration. In 194I she was seen by a surgical specialist who found evidence of a pan-sinusitis and drained both maxillary antra, which were full of pus. During this operation she was observed to cough up a mass of thick greenish pus from the lower respiratory tract. Bronchiectasis was suspected, and X-ray examination of the chest confirmed this suspicion. She was treated by postural drainage, and an autogenous vaccine, prepared from a culture of the sputum, was also employed; the resulting improvement in her symptoms, however, fell short of expectations. Her family were anxious to send her to Switzerland, but the possibility of surgical treatment had been considered, and I was asked to see her with a view to bronchography so that the whole question might be adequately ventilated.

Figs. 3 and 4 illustrate the condition of the bronchial tree on the left side in November, 1945. The branches to the lower lobe show undoubted saccular bronchiectasis, the branches to the middle lobe are also dilated. Bronchograms of the right side appeared more or less normal, but careful scrutiny of the lower lobe bronchi showed that the posterior basic branches were by no means beyond suspicion, some distortion and slight dilatation being evident. For this reason it was felt that the prospects of satisfactory results from a left lower lobe and lingula lobectomy were not altogether favourable, and it was decided to allow the patient to go to Switzerland to a moderately high altitude, with the proviso that the question of operative intervention at a later date might have to be considered.

Eventually she went to Arosa early in 1946, and continued her studies there ; she improved considerably in general health and her catarrhal symptoms cleared up. In February, 1947, she was taken ill with acute fever and respiratory distress following an attack of varicella. I was not able to get a very accurate account of her clinical picture at this time, but so far as I could gather from the rather inadequate notes available, she appears to have had a pneumonia (sic), and X-ray examination showed bilateral pleural effusion. Exploration of the right pleural cavity revealed the presence of clear fluid, and this exudate eventually resolved completely. Since abnormal physical signs persisted on the left side, and it was thought that fluid was present here also, the left side of the chest was explored on several occasions, at first with negative result; later, however, a small amount of pus was withdrawn; despite this fact, no further steps seem to have been taken for nearly a month. The patient was removed from Arosa in April and was transferred to a clinic in Zürich where further exploration of the left side of the chest revealed a pyothorax, and intercostal drainage was effected by insertion of a rubber catheter. There was evidence of a broncho-pleural fistula, and the drainage tube was left in situ and the patient returned to England. The condition of the chest just prior to drainage is shown in Fig. 5.

Towards the end of June, I947, I was asked to see her urgently in consultation with her own doctor, who was anxious about her as she had begun to complain of headache and photophobia with occasional vomiting; her temperature had risen to $103^{\circ}$. The possibility of a cerebral abscess was, naturally, very much in her doctor's mind. When I saw her she was obviously very toxic; she was still complaining of some headache, though the temperature was not then so high; although worried with the pain and obviously ill, she had no mental confusion, and careful examination of the central nervous system at that time revealed no localizing signs. There was very slight blurring of the nasal edges of the optic discs, but no definite papilloedema. The intercostal tube was still in situ, but drainage of the pleural cavity was intermittent, the total amount of discharge being quite small. The X-ray appearances of the chest at this stage are shown in Fig. 6. I was unable to satisfy myself at this time that there were sufficient grounds for a diagnosis of cerebral abscess, and felt that with adequate drainage of the infected pleural cavity the general toxaemia, to which I attributed the cerebral symptoms, might well clear up completely. Arrangements were made for her transfer to the Brompton Hospital as soon as a bed was available.

Within a few days of this her condition became suddenly much worse and after an urgent communication from her doctor she was brought to London by ambulance and admitted to Brompton as an emergency on July 6 . She stood the long ambulance journey well, but on arrival at the hospital was somewhat exhausted. No definite signs of any local lesion of the central nervous system were apparent, but she was extemely toxic and examination of the urine showed marked acetonuria. A glucose drip saline (intravenous) was started and 50,000 units of penicillin were given by intramuscular injection. 
The following day she was conscious and rational, but complained of severe frontal headache radiating backwards to the occiput; there was also some pain and stiffness of the back of the neck. The general condition at this time was suggestive of a severe disturbance of the nervous system, and, despite the presence of definite focal sepsis in the chest, the possibility crossed my mind that this might be a case of tuberculous meningitis with a long prodromal period. On lumbar puncture there was no increase in the pressure ; the cerebro-spinal fluid was opalescent. Penicillin (10,000 units) was introduced into the spinal canal. Examination of the fluid showed 360 cells per c.mm. (polymorpho-nuclears 37 per cent., lymphocytes $6 \mathrm{r}$ per cent., monocytes 2 per cent.). The protein content was $180 \mathrm{mg}$. and the chlorides 710 mgm. per cent. The fluid was sterile. Although there was no characteristic diminution of the chlorides, yet the presence of so many lymphocytes in the fluid in conjunction with the clinical picture of meningeal irritation and the long history of increasing toxaemia (which seemed incommensurate with the degree of focal sepsis present), appeared to fit in with a diagnosis of tuberculous meningitis. It had been alleged by the medical authorities at Arosa that on one occasion tubercle bacilli had been recovered in a specimen of the sputum; I had no really satisfactory proof of this and could only regard such evidence as circumstantial and of doubtful value.

On July i I a second lumbar puncture was done. The fluid was still opalescent. There were I50 cells per c.mm. (polymorphonuclears 30 per cent., lymphocytes 70 per cent.). The protein was $80 \mathrm{mgm}$. and the chlorides $640 \mathrm{mgm}$. per cent. The following day she complained of slight diplopia ; there was still no definite papilloedema though the edges of the discs were not quite sharp and clear. The same evening I asked Dr. Russell Brain to see her with me. He agreed that in view of the lymphocytic content of the spinal fluid, the persistent fever, and the long and rather indefinite clinical history, tuberculous meningitis could not be excluded; he was, in fact, inclined to favour this diagnosis in spite of the absence of bacteriological proof, though as a possible alternative he suggested there might be a condition of superficial venous thrombosis following the focal sepsis in the chest. The headache continued for some days with varying severity, as did also the diplopia, and by July 20 she was extremely drowsy and restless, later becoming delirious. She lay partly curled up in bed, resenting interference, with definite rigidity of the neck muscles and with a positive Kernig's sign ; she gave a frequent and characteristic cry at intervals, her whole condition presenting a classical picture of tuberculous meningitis. Lumbar puncture was again done the same afternoon, Io cc. of fluid being removed with slight resulting improvement in the patient condition. This fluid contained 700 cells pe्c c.mm. (polymorphonuclears 32 per cent., lympho: cytes 68 per cent.). The protein content was $120 \mathrm{mgm}$. and the chlorides $680 \mathrm{mgm}$. per cent (one acid-fast bacillus was found on examination of direct smear).

For a few days after this there was a markea improvement in her general condition, the head ache being less and consciousness having returned, though diplopia was still present. On July she had two epileptiform attacks, one at $8.30 \mathrm{a} . \mathrm{m}$ the second at I I.30 a.m. The fits commenced the left leg and spread to the left arm and then the right side of the body ; there was associated. loss of consciousness, cyanosis, and biting of thio tongue. This was the first suggestion of an localizing symptoms, and Dr. Russell Brain, wh kindly saw her again with me on the following day then thought that the evidence seemed much less indicative of tuberculous meningitis and more if favour of a cerebral abscess occurring as a bloo $\bar{q}$ borne metastasis from the pyogenic infection if the chest. We agreed that examination by ventri culography was indicated and the next day she was seen by Mr. Wylie McKissock who had boen called in in consultation.

After the usual trephine he explored the regton of the right occipital lobe and aspirated 4 or 5 ;Ce of pus. He then inserted $\mathrm{I}$ cc. of thorotrast an penicillin into the abscess cavity and the wound was closed in three layers. The site of the absceso is illustrated in Figs. 7 and 8 (radiograms taken on July 30 , shortly after operation). The patient $\frac{2}{8}$ general condition following this exploration re mained satisfactory, no marked disturbance of the nervous system being observed. Bilateral papiR loedema was now noted, chiefly in the nasal halves of the discs. Cultures of the pus aspirated re mained sterile for $4^{8}$ hours, after which a fe pyogenic cocci were grown. Sulphamezathine and penicillin were given daily. On September the condition of the abscess cavity was as seen in Figs. 9 and ro, and on September $14 \mathrm{M}$. McKissock again operated and removed the abscess sac by gentle dissection. The patien stood the operation well, and thereafter made unf interrupted progress, rapidly resuming her normạl cerebral functions, and exhibiting no further signe of untoward disturbance, though slight papits loedema persisted. The condition of her chesf remained more or less the same, the last two radice grams (July 16 and September I6) being shown bo Figs. I I and 12. On September 20 it was noted that air was still blowing in and out of the empyem tube. 


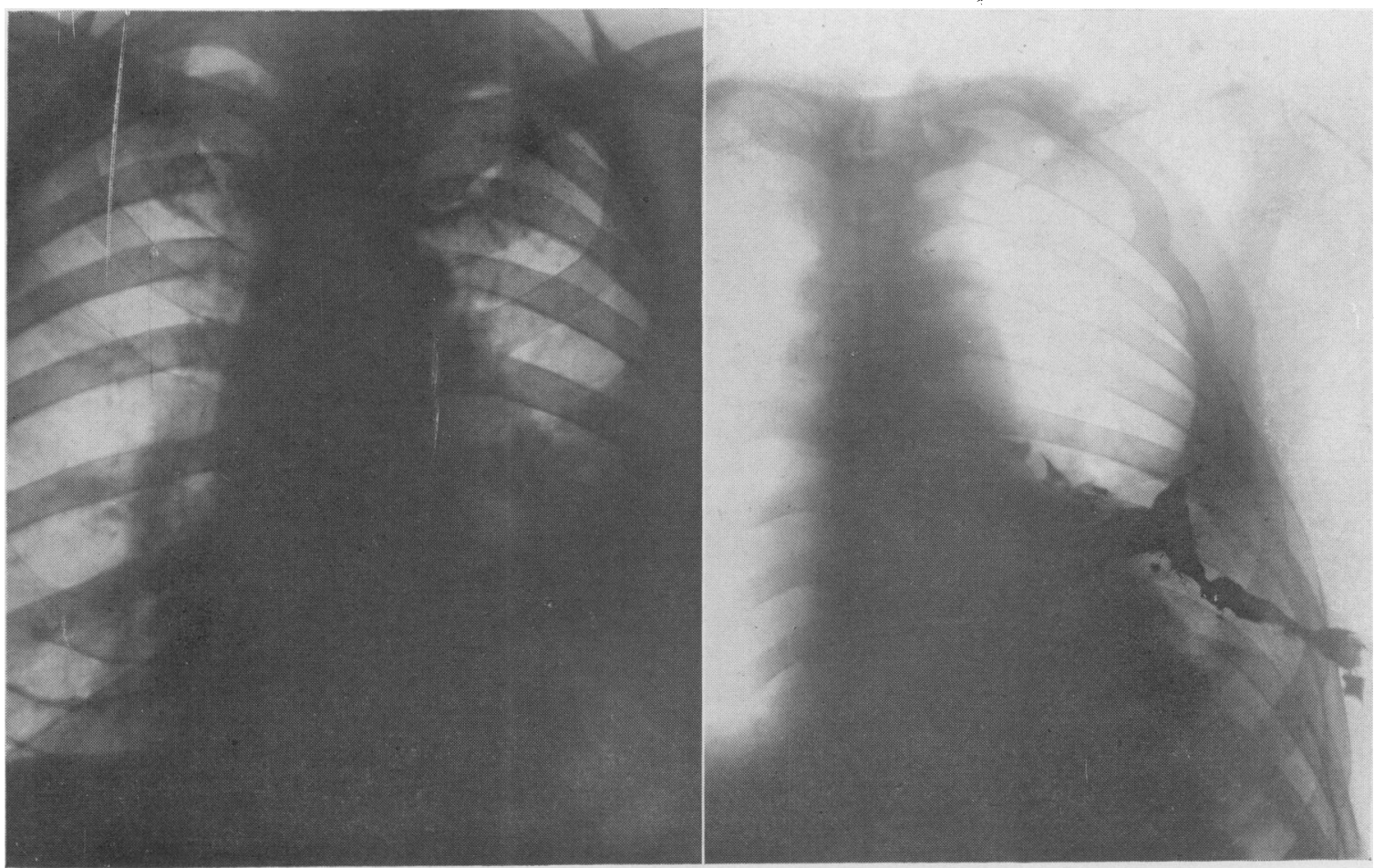

FIG. I.-Radiogram of chest from Case I posteroanterior view).

Fig. 2.- Same Case as Fig. I after injection of neohydriol to show extent of sinus.

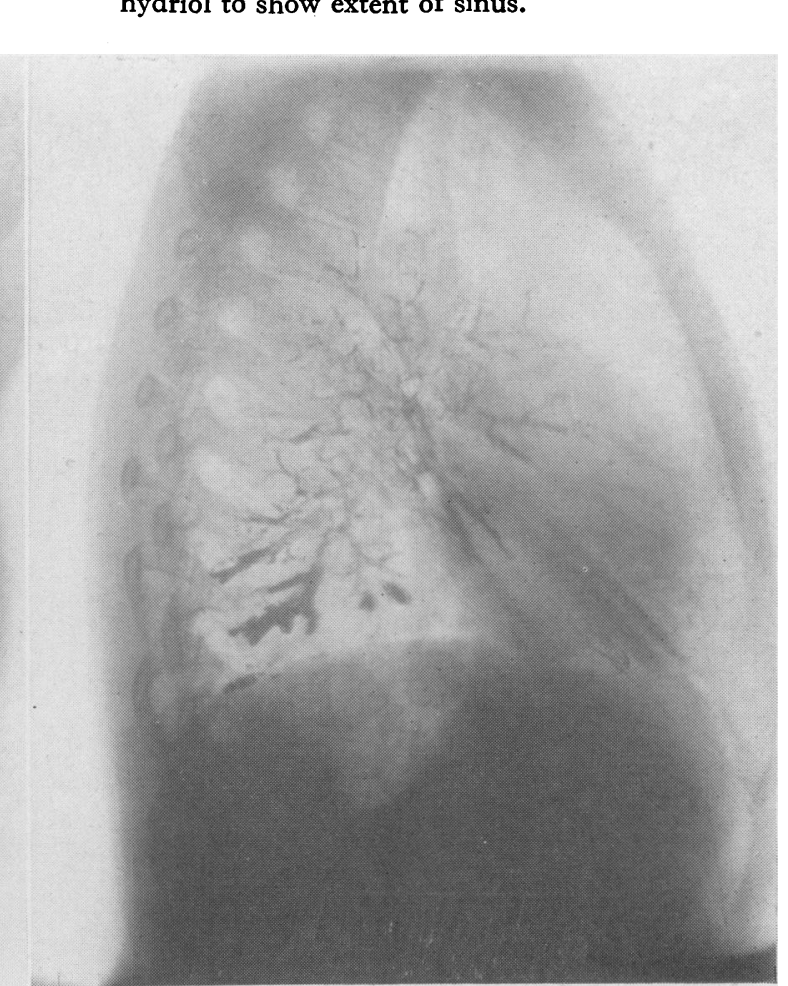

Fig. 4.-Same Case as Fig. $3(7 / 11 / 45)$ (lateral view).

C1
FIG 3.-Bronchogram of Case $3(7 / 11 / 45)$ (posteroanterior view). 


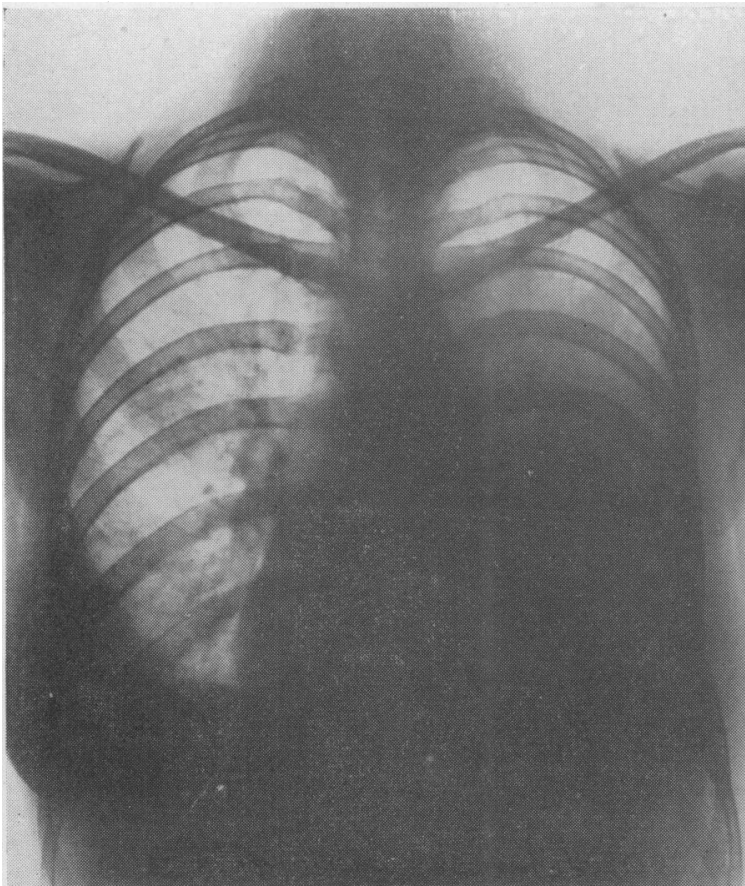

FIG. 5.-Radiogram of chest from Case 3 (9/5/47) before aspiration.

FIG 6.-Radiogram of chest from Case $3\left(3 / 7^{\prime} 48 \overrightarrow{0}\right.$ drainage tube in left pleural cavity.

Fig. 7.-Radiogram of skull from Case $3(30 / 7 / 47)$ after introduction of thorotrast into abscess cavity.

FIG. 8.- Same as Fig. 7 (lateral view). 
February 1948 DAVIDSON : Cerebral Metastasis in Association with Intrathoracic Disease

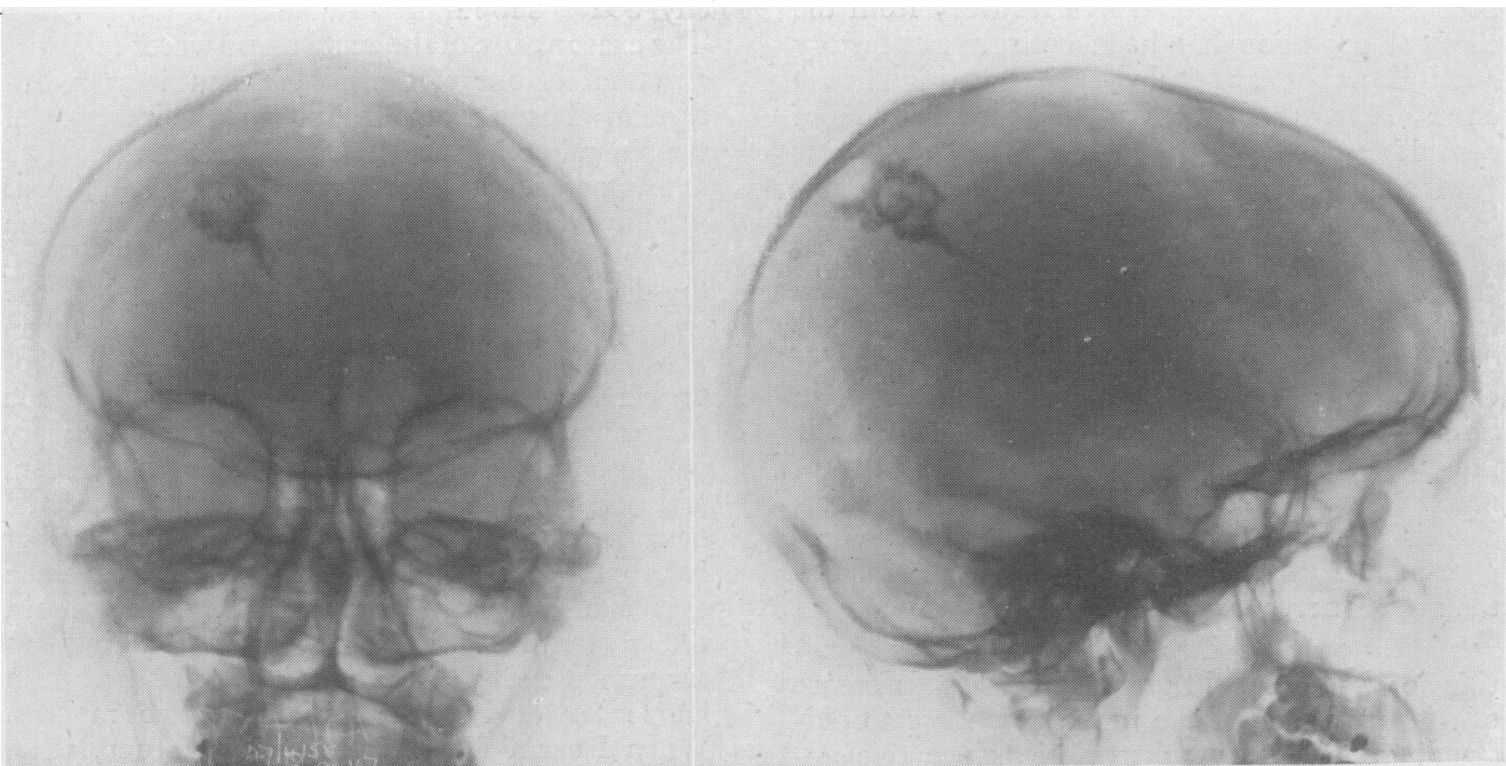

Fig. 9.-Radiogram of skull from Case 3 (9/9/47) Fig. 10.-Sane as Fig, 9 (latera! view'. showing abscess cavity well outlined. 
Since then the intercostal drainage tube has been removed. The patient's recovery from the cerebral operation has been entirely satisfactory and it is proposed to deal with the condition in the chest later on after a suitable period of convalescence.

\section{Comment}

The primary object of this article was the recording of the above three cases, the first of which is a fairly typical example of a brain abscess occurring after many years as a complication of chronic empyema, the other two presenting certain initial difficulties in diagnosis sufficiently outside the average clinical experience to be worthy of mention. Several other points, however, arise, especially from the anatomical standpoint, regarding the metastasis of intrathoracic lesions to the central nervous system.

The autopsy findings in Case 2 came as something of a surprise. I have postulated the existence of a tuberculoma of the brain, secondary to oldstanding pulmonary tuberculosis, since this appeared on the whole the most reasonable hypothesis to fit the clinical and anatomical facts. Kinnier Wilson (1940) noted the diminishing incidence of brain tuberculomata and gave a table showing their incidence among brain tumours according to various authors. Out of a total of 2,190 tumours classified, the tuberculomata numbered 79, i.e., 3.6. per cent., against which Wilson has quoted Starr's compilation in 1890 . of 500 brain tumours which yielded a percentage of tuberculomata as high as $\mathbf{3 2 . 2}$. They are generally understood to be isolated tuberculous lesions. According to Vines (1940) they are unassociated at first with any generalized tuberculous process, though it is supposed that they may occasionally lead, after a long interval, to tuberculous meningitis or to miliary tuberculosis of general distribution. It will be remembered that in this case the pulmonary lesions were of different dates, the apical fibrosis being obviously of very long standing while the discrete lesions in the upper and middle zones of the lungs were undoubtedly more recent. Whether the spread to these areas of the lungs and to the temporo-sphenoidal lobe of the brain was more or less simultaneous, and what was the date of its occurrence, can only be a matter of conjecture; no objective symptoms of manifest disease were observed in this patient until a comparatively short period before his death from cerebral abscess with a terminal pneumonia.

The clinical story of Case 3 was distinctly unusual. It seems hardly likely that this girl would have developed an abscess of the brain as a result of the bronchiectasis pure and simple; when she first went abroad she had no constitutional dis- turbance, and there was little or no evidence of any active suppurative lesion within the chest 3 The exact nature of the acute phase which followed an attack of one of the milder exanthems is un $\frac{.}{.}$ certain. I cannot help feeling that the infection of the pleural cavity, which led to the formation of an empyema, must have been a result of injudicious: needling of the chest in circumstances in which such a procedure was really contraindicated. Fromb the dates of her movements it is evident that the empyema cannot have been present for more than two or three months at most before the onset of the cerebral symptoms ; it can hardly be described as belonging to the chronic variety in the ordinaryw sense of the term. It was partly for this reasons and partly because of the absence of any definit neurological signs when I saw her soon after hes: return to England, that I hesitated to conclude that she had an infective cerebral metastasis, $N$ though the history of headache and vomiting was suspicious enough in the light of what had been happening during the preceding two months. When I examined her at the end of June, r 947 ,she was, despite the toxaemia, mentally alert and able to give a clear and intelligible account of most of her experiences abroad; such a picture is in striking contrast to that usually observed in cases of cerebral ahscess.

Walshe (I947) lays stress on the change $\mathrm{in}$ mental alertness and emotional tone as one of the most striking early indications of the formation of an abscess in the brain. ' The patient,' he says, ' tends to be an ineffective witness when questioned as to his illness, his memory is poor, and his $\underset{\varrho}{\varnothing}$ capacity for sustained attention manifestly im $\overrightarrow{\overrightarrow{0}}$ paired ; he is apathetic and may even be drowsy ;을 he may confess to headaches, but no very precise? account of his symptoms can usually be obtainedô. from him.' Even later, when the increasingo pyrexia and vomiting made evident the urgency of her condition, the state of the cerebro-spinal fluido was more suggestive of meningitis than of cerebral abscess, and the suspicion of tuberculousô meningitis raised by the insidious history and the lymphocytic cellular content of the fluid was to을 some extent strengthened by the allegation (for $>$ which I had no adequate proof), of the finding of tubercle bacilli in her sputum on one occasion in the clinic at Arosa.

In the three cases just quoted the primary lesion 0 within the chest was inflammatory. It remains tow say a few words about the secondary lesions in the brain in connection with primary bronchogenico carcinoma. That the brain is a frequent site for secondary deposits in this condition is well known.? Oschner and DeBakey (1942) give a graphic representation of metastasis of primary lung cancer $\overrightarrow{\bar{D}}$ based on 3,047 collected cases in which the brain, $\frac{\mathbb{P}}{9}$ 
which they list eighth out of 17 different organs, accounts for 16.5 per cent. Dosquet (192I) quoted by Frissell and Knox (1937) gives figures from autopsies in the pathological departments in Berlin and Kiel showing metastasis in the brain in $3 \mathrm{I} .4$ per cent. of a series of 109 cases of bronchogenic carcinoma ; in contrast with this he refers to 2,519 cases of cancer of other organs, among which cerebral metastasis was found in only 1.6 per cent. of the Berlin cases and 0.6 per cent. of the Kiel cases. Fried and Buckley (1925) found metastasis in the central nervous system in 15 out of 37 patients with bronchogenic carcinoma, i.e., in approximately 40 per cent. The prominence of neurological symptoms from secondary cancer in patients in whom a primary bronchial growth has been silent and entirely unsuspected is a striking phenomenon to which attention has been frequently called in neurological literature. Ferguson and Rees (1938) emphasized this in a record of nine cases observed at the National Hospital over a period of ten years. In five of these cases neurological symptoms were the first manifestation of disease ; in the remaining four, neurological and chest symptoms appeared almost simultaneously. The nine cases were taken from a total series of 29 tumours of which the secondary deposits were causing signs or symptoms (i.e., $3^{1}$ per cent.). The frequency of cerebral metastasis in bronchogenic cancer is such that in most neurological clinics $\mathrm{X}$-ray examination is now recognized as a necessary part of the routine investigation in all cases showing symptoms or signs suggestive of tumour.

In conclusion it may be of interest to consider cerebral tumour and intrathoracic suppuration together in connection with the aetiology of cerebral metastasis and especially with reference to the paths by which the secondary deposit reaches the brain. Cerebral abscess secondary to bronchiectasis or chronic empyema is generally regarded as due to the passage of a septic embolus, and some uncertainty has been felt as to the route by which such passage occurs. When a septic clot is detached from some distant focus in the body and enters the venous circulation, the usual filter in its path is the pulmonary vascular bed-the occurrence of pulmonary infarction after pelvic operations for example is well known. How is it then that in cases such as we have been considering particles reach the brain without being caught by the pulmonary capillaries ? Oschner and DeBakey, discussing this in case of lung cancer pointed out that when the lesion was primarily in the lung, no such barrier was present when once the tumour cells had entered the pulmonary veins, when the route to the arterial circulation and so to the brain became direct. Simpson (1929) noted thrombosis of veins by tumour cells in 29 out of 139 cases (approximately 17 per cent.), and found that the pulmonary vein 3 were often affected both by thrombosis and by direct invasion of the growth.

A good deal of experimental work has been carried out in order to elucidate this point, especially by Batson (1940) who lays considerable stress on the part played by the vertebral veins in the spread of secondary lesions. After injection of opaque material in solution into the breast veins of a female cadaver he found the material in the clavicles, the intercostal veins, the head of the humerus, the cervical vertebrae, the transverse cranial venous sinus, and in the superior longitudinal sinus; some of it also appeared in the azygos vein and in the superior vena cava. $\mathrm{He}$ has suggested that the vertebral veins should be recognized as a definite system in addition to the portal, caval, and pulmonary systems. He points out that after straining, coughing, etc., the blood is pressed out of the thoracic cavity, and that tumours and abscess of the thoracico-abdominal wall, as well as tumours of the lung, having connections with this venous system may give rise to metastasis at any point in it without involvement of the portal, caval, or pulmonary systems. His conception of the application of this in cases of bronchogenic carcinoma is particularly fascinating. 'The primary lesion,' he says, 'provides the tumour cells, and the stimulus for the cough which causes a flow from the bronchial veins, especially the posterior one, into the spinal veins rather than into the veins of the right heart.' The same explanation holds good for the occurrence of abscess in the brain secondary to lung abscess ; 'the posterior bronchial vein and vertebral veins, with the ever-present cough, appear to present the plausible route of extension.'

Martin (194I) in his observations on superior longitudinal sinus thrombosis following childbirth quotes Batson's work and concludes that fragments of clot may be carried up to the superior longitudinal sinus by way of the vertebral venous system and there act as a nucleus for the clot which forms in the sinus.

Collis (1944) in a summary of the literature on this subject, to which he has added observations from his own cases, makes the point that for thrombosis to extend from an inflammatory process in the lung or pleural cavity to the vessels of the chest wall, the adhesions between lung and chest wall must have become vascularized. When the thrombosis reaches the walls of larger veins, he says the emboli are likely to affect the intercostals mainly since the distribution of the bronchial veins is relatively limited. He regards the ultimate distribution of the embolus as de- 
pending on whether or not conditions favour a reversed flow of blood in the spinal veins, in which case it may enter this system and be carried to the brain-otherwise it may be carried by the azygos veins to the superior vena cava, and so be caught in the pulmonary network, where it is relatively harmless.

\section{Summary}

Three cases are described in which a metastatic abscess in the brain developed secondary to focal infection in the chest.

Difficulties in differential diagnosis in two of $\frac{3}{\mathbb{D}}$ these are described and briefly discussed.

The occurrence of secondary deposits of growth in the brain in cases of bronchogenic carcinoma is $\overrightarrow{\overrightarrow{\vec{D}}}$ reviewed, and reference is made to recent observa- $\bar{O}$ tions on the anatomical paths by which metastatic 흐 deposits from intrathoracic lesions travel to the $\frac{\bar{m}}{\sigma}$ central nervous system.

\title{
BIBLIOGRAPHY
}

BATSON, O. V. (1940), Ann Surg., 112, 138.

BRAIN, W. R. (1947), 'Diseases of the Nervous System,' 3rd edition. Oxford Univ. Press.

COLLIS, J. L. (1944), Fourn. Thor. Surg., 13, 445.

DOSQUET (1921), Virch. Arch. f. path. Anat., 234, 481 .

FERGUSON, F. R., and REES, W. E. (1938), Lancet, I, 738.

FRIED, B. M., and BUCKLEY, R. C. (1925), Arch. Int. Med.,

FRISSSELL, L. F., and KNOX, L. C. (1937), Amer. Fourn. Cancer, 30, 235 .

JEX-BLAKE, A. J. (1920), Brit. Med. fourn., 1, 591.

KENT, E. M., and BLADES, B. (1942), Fourn. Thor. Surg., 2, 434.
MARTIN, J. P. (194I), Brit. Med. fourn., 2, 537.

NICKERSON, D. A. (1935), New Engl. Fourn. Med., 213, 228. OSCHNER, A., and DEBAKEY, M. (1942), fourn. Thor. Surg. 2,357

SIMPSON, S. L. (1929), Quart. Fourn. Med., 22, 413.

VINES, H. W. C. (1940), 'Green's Manual of Pathology,' I6th WALSHE, F. M. R. (1947), 'Diseases of the Nervous System,' 5 th $\mathrm{N}$ edition, p. 89. Edinburgh. E. \& S. Livingstone, Ltd. WILSON, S. A. K. (I940), 'Neurology,' Vol. I, p. 593. London. î Edw. Arnold \& Co.

\section{SOME CLINICAL AND SOCIO-MEDICAL OF CARDIOVASCULAR DISEASE}

\author{
By Edmund Finsterbush, M.D. (Vienna), M.R.C.S. (Eng.), L.R.C.P. (Lond.) \\ Consulting Cardiologist to the Ministry of Pensions
}

The present state of affairs in respect of diagnostic, remedial, preventive, and socio-medical arrangements for cardiac patients is comparable to that regarding tuberculosis prior to the institution of tuberculosis dispensaries and tuberculosis officers in this country some $4 \circ$ years ago.

A few historical data may briefly illustrate the development of tuberculosis services which contrasts so strikingly with the complete lack of similar arrangements for cardiac cases.

The control of tuberculosis was initiated by a voluntary system of notification of phthisis by the Metropolitan Borough of Finsbury in 1900 under the then Medical Officer of Health, Dr. George Newman. The compulsory notification of all forms of tuberculosis followed in 1912 under the Public Health Regulations.

The departmental Committee under the chairmanship of Mr. Waldorf Astor, M.P., in one of their reports (1913) advised that " the aim should be that not a single case of tuberculosis should be uncared for in the community, and that whatso-을 ever services the scheme provides should be avail able for all cases of the disease.' Up to that time, $\frac{}{3}$ the scheme consisted of tuberculosis dispensaries, the first one founded by Dr. Robert Philip (after-o wards Sir Robert Philip) in 1887 , sanatoria, hospitals, farm colonies, open air schools, etc.

Under the Public Health Act (Tuberculosis $?$ Act) 1921 the local authorities were directed to arrange treatment, aftercare, and supervision of $\tilde{\sigma}$ tuberculosis patients.

The remarkable progress in the anti-tuberculosis services is evident from the following figures. In $\mathrm{\omega}$ I9I I there were 5700 sanatorium beds for tuberculosis ; in 1923 there were 442 tuberculosis dispensaries in England, and 249 tuberculosis officers ; in 1936 there were 459 tuberculosis ${ }^{+}$ dispensaries, some 400 tuberculosis officers, and $\frac{{ }^{\circ}}{\circ}$ 26,773 sanatorium beds. 